\title{
DUAS DÉCADAS DE CONJUNTURA ECONÔMICA, DE (DES)EMPREGO INDUSTRIAL E DE INSERÇÃO DOS PROFISSIONAIS DA INFORMAÇÃO NO MERCADO DE TRABALHO
}

\author{
Paulo de Martino JANNUZZI ${ }^{1}$ \\ Fernando Augusto Mansor de MATTOS 2
}

\begin{abstract}
RESUMO
O objetivo do artigo é trazer elementos empiricos para uma reflexão sobre as perspectivas do mercado de trabalho dos Profissionais da Informação na Indústria e demais setores da economia brasileira. Para tanto, o texto está dividido em duas partes. Inicia-se com uma análise retrospectiva da conjuntura econômica ao longo das últimas décadas, destacando o papel das politicas governamentais na promoção do desenvolvimento econômico e industrial brasileiro, e depois, atendo-se às duas décadas mais recentes, ressalta-se o impacto das sucessivas conjunturas econômicas dos anos 80 e 90 sobre o comportamento do emprego e em especial do emprego industrial. Na segunda parte analisa-se o comportamento da demanda por Profissionais da Informação, o nivel de rendimento e inserção setorial com base nos dados de pesquisas nacionais do IBGE. Procura-se mostrar que, dadas as baixas taxas de crescimento econômico e a elevada vulnerabilidade externa que tem caracterizado a economia brasileira, mesmo os Profissionais da Informação têm tido crescentes dificuldades para se inserirem no mercado de trabalho brasileiro e nele construirem uma carreira estável e promissora.
\end{abstract}

Palavras-chave: economia brasileira; indústria; mercado de trabalho; profissionais da informação.

\begin{abstract}
The purpose of this paper is to present an empirical evidence about the behaviour of the Information Workers 'labor market in the manufacture and the other sectors of Brazilian economy. The article is divided into two parts. It begins with a retrospective analysis of Brazilian economic conjuncture over the last decades, pointing out the role of the government in the economic and industrial improvement of the country, and discussing the effects of the economic conjuncture over employment, specially in the manufacture sector. In the second part, it is analyzed the demand for Information workers, the level of revenue and then insertion in Brazilian labor market, according to the data from national household surveys. The main idea in the article is to show that even Knowledge workers have found barriers to get or keep their jobs in a context characterized by low economic growth rates and the external vulnerability of Brazilian economy.
\end{abstract}

Key words: brazilian economy; manufacture; labor market; information workers.

1. Professor do Programa de Mestrado em Biblioteconomia e Ciência da Informação da PUC-Campinas. Mestre em Administração Pública pela FGV-SP e Doutor em Demografia pela UNICAMP.

2. Professor da Faculdade de Ciências Econômicas, Contábeis e Administrativas da PUC-Campinas. Mestre e Doutor em Economia pelo Instituto de Economia da UNICAMP. 


\section{INTRODUÇÃO}

O objetivo deste artigo é apresentar um análise empírica do comportamento do mercado de trabalho dos Profissionais da Informação no Brasil nas duas últimas décadas, enfocando, em especial, a inserção dos mesmos no setor produtivo. Com base em fontes de dados de pesquisas de maior representatividade populacional que as normalmente empregadas em trabalhos dessa natureza, apontamos evidências que relativizam, em certa medida, a crença generalizada que nesse período estes profissionais têm garantido uma inserção e mobilidade ocupacional mais virtuosa que outras categorias mais tradicionais.

$\mathrm{Na}$ realidade, como se procura mostrar, nem mesmo boa parte das ocupações diretamente vinculadas ao novo paradigma produtivo que se convencionou chamar de Sociedade Pós-Industrial, Sociedade Cibernética, Sociedade da Informação ou Sociedade do Conhecimento foram poupadas do processo de precarização que a maior parte da mão de obra brasileira vivenciou desde os anos 80. Dada a dimensão da crise econômica das duas últimas décadas e dadas as perspectivas incertas colocadas pela elevada vulnerabilidade externa que tem caracterizado a economia brasileira, especialmente desde a adoção do Plano Real, mesmo os profissionais que estão entre os mais bem qualificados do mercado de trabalho brasileiro, como é o caso dos Profissionais da Informação, têm tido crescentes dificuldades para se inserirem no mercado de trabalho brasileiro e nele construírem uma carreira estável e promissora.

Vinte anos de acelerado desenvolvimento tecnológico e introdução de novas tecnologias, acompanhados de baixo crescimento econômico e da produção industrial, de aumento da parcela de mão de obra em desemprego ou com salários mais baixos já deveriam ter mostrado que o futuro pode não ser tão promissor, nem mesmo para os online workers de hoje.
Há quem chegue a duvidar que as novas tecnologias e os novos meios de informação estejam criando algum acréscimo economicamente relevante de novos empregos no mercado de trabalho, haja vista a racionalização de postos de trabalho que acompanha este processo. Como bem observa German (2000):

“As novas tecnologias computadorizadas possibilitam agora a substituição da inteligência humana - em numerosos setores da economia, as pessoas são desalojadas por máquinas pensantes .... isso significa que o desenvolvimento de novo hardware ou software permite em principio que qualquer pessoa que trabalhe com as mãos ou a cabeça se possa tornar desempregada ou desqualificada.

... Empregos preponderadamente pouco qualificados, com atividades rotineiras, são eliminados por medidas de racionalização, ao passo que empregos em atividades inovadoras são mais seguros - conquanto que correspondam aos perfis dinâmicos das exigências da indústria da informação. Pois mesmo os modernos Knowledge workers, entre os quais contam-se hoje executivos, engenheiros, juristas, médicos, corretores de bolsas de valores ou professores universitários, em princípio não ficam ao abrigo de possibilidades de racionalização ou dos efeitos subseqüentes de longo alcance sobre a estrutura socioeconômica. "(German, 2000 pp. 24-25).

Entendendo que uma reflexão sobre a inserção ocupacional dos Profissionais da Informação não pode ser feita sem levar em conta uma análise da trajetória recente da política macroeconômica brasileira e de seus efeitos sobre todos os demais setores, iniciamos este artigo com uma análise sucinta da trajetória econômica do Brasil no século XX. Destacamos momentos específicos da conjuntura econômica 
a partir dos anos 80 e os seus impactos sobre o comportamento do emprego e em especial do emprego industrial. Depois desta análise econômica retrospectiva, passa-se então, propriamente, à análise do comportamento do mercado de trabalho dos profissionais da chamada "Terceira Revolução Industrial”.

\section{A CONJUNTURA ECÔNOMICA E O EMPREGO INDUSTRIAL}

Analisando os dados de crescimento econômico de diversos países, podemos afirmar que o Brasil foi o país que teve a maior taxa média anual de crescimento real do Produto Interno Bruto entre 1900 e 1980, e quando são considerados os dados dos anos 80 , perde apenas para o Japão. Como se pode verificar no Figura 1, onde se traz as taxas médias anuais de crescimento do PIB ao longo do século passado, é possível ver que as décadas de 1950 (que inclui o segundo Governo Vargas e o governo de Juscelino) e de 1970 são as que apresentam as maiores taxas médias de crescimento do Produto Interno Bruto (PIB) real. Na década de 1950, foi implementada a indústria de base no Brasil, com a chegada da indústria automobilística e com a instalação de importantes setores da indústria de bens de capital (máquinas e equipamentos), impulsionando nosso desenvolvimento industrial (em diversos setores, como o químico, eletrodomésticos, entre outros) e agrícola (a mecanização da agricultura passou a acelerar-se nesse período, permitindo importantes ganhos de produtividade no setor, os quais se ampliariam nas décadas seguintes). Nos anos 50, a sociedade brasileira passou por intensas modificações, destacando-se a acelerada urbanização, o surgimento de uma classe média numerosa e a criação de uma grande quantidade de novas profissões, não somente no pujante setor industrial, mas também no setor de serviços, destacando-se os serviços ligados às atividades comerciais, bancárias e no apoio às atividades industriais e de infra-estrutura urbana. A rigor, as profisssões ligadas à coleta, organização, análise e disseminação de informações tomam impulso nesta época, e são formadas por profissionais ligados tanto às novas atividades industriais, quanto ao moderno e emergente setor de serviços e também - é muito importante destacar - ao setor da burocracia estatal planejadora, que toma grande impulso nos governos desenvolvimentistas de Vargas e $\mathrm{JK}^{3}$, quando, entre outras instituições, foram criadas (ou ampliadas), por exemplo, o BNDE, Petrobrás, Ministério do Planejamento, entre outros ${ }^{4}$. Data desse período o fortalecimento do IBGE, que havia sido criado em 1936, e que a partir dos anos 60 começa a implementar diversas pesquisas amostrais com finalidade de subsidiar a tomada de decisões de política macroeconômica e formulação de políticas públicas.

Nos anos 70, tivemos o chamado "Milagre Brasileiro", que, na verdade, iniciou-se no final da década de 1960, mas atingiu seu auge entre $1970 \mathrm{e}$ 1973, quando a produção industrial chegou a crescer à taxa anual média de cerca de $13,6 \% 5$. Entre $1974 \mathrm{e}$ 1979, apesar da mudança drástica ocorrida no cenário internacional (duas crises do petróleo, desaceleração das economias dos países desenvolvidos), a economia brasileira ainda manteve-se em trajetória de elevado crescimento (embora menores do que os excepcionais anos do Milagre Brasileiro), graças especialmente à política de desenvolvimento industrial adotada no governo Geisel, que consolidou o chamado processo de substituição de importações da economia brasileira, com o impulso dado aos setores petroquímico, químico, de extração mineral e de geração de fontes alternativas de energia (como o

3. Ver Ianni (1986).

4. Empresas estatais que tiveram importante papel no desenvolvimento brasileiro também foram criadas nessa época ou um pouco depois, durante a década de 1960 ou nos governos militares. O importante a destacar aqui, para os propósitos de nosso estudo, é que, em todas estas estatais ou ministérios, profissionais ligados à coleta, organização, análise e disseminação e informações passaram a ser demandados em grande quantidade e puderam fazer carreiras profissionais promissoras durante toda uma vida.

5. A taxa anual de crescimento do produto industrial brasileiro em 1970 foi de 11,9\%; em 1971, novamente de 11,9\%; em 1972, de 14,0\% e, em 1973, atingiu 16,6\% (dados do IBGE). 


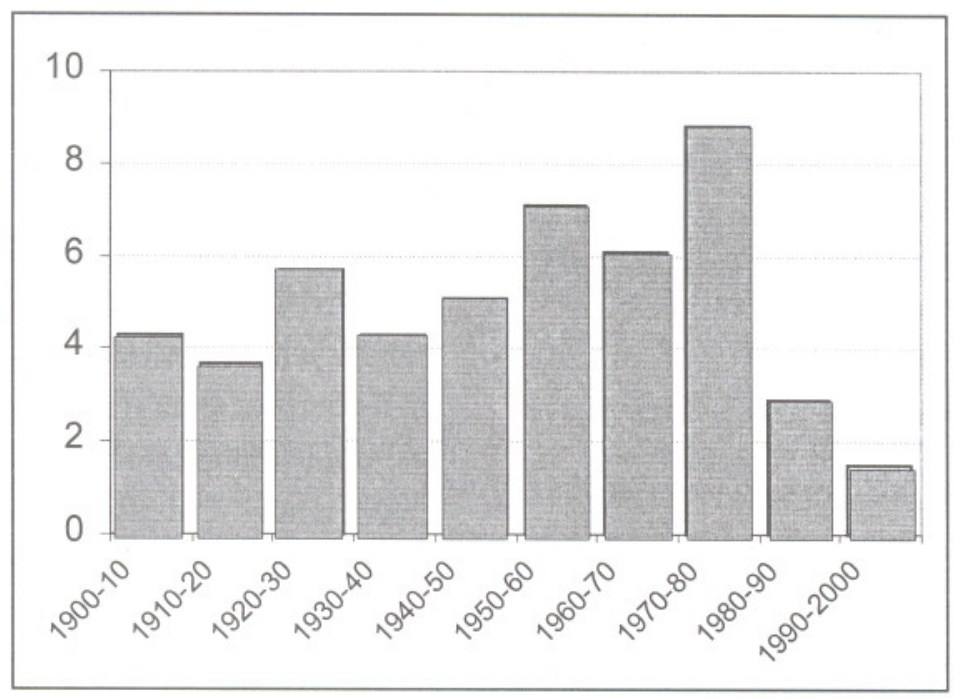

Figura 1. Taxa média anual de crescimento do PIB real Brasil - décadas do século XX.

álcool -o que teve mais sucesso, e a energia nuclear) ou mesmo de ampliação do setor de geração e distribuição de energia hidrelétrica. O período entre 1950 e 1980, portanto, exibiu destacado dinamismo econômico e teve na expansão do setor industrial o motor do desenvolvimento brasileiro, com efeitos positivos, em termos econômicos, "transbordando" para os demais setores da economia (agropecuária, extrativismo mineral e vegetal, setor de serviços inclusive os financeiros). Em todo esse período, foi decisiva a atuação do Estado Nacional, quer seja na forma de produção direta de bens e insumos para o setor industrial (através das empresas estatais), quer seja na elaboração de políticas creditícias, fiscais e de comércio exterior que favoreciam a expansão dos setores industriais priorizados por diferentes planos econômicos de desenvolvimento (como, por exemplo, no Plano de Metas de JK, ou no II PND de Geisel).

\section{Os anos 80: a década perdida}

Os anos 80 caracterizaram-se por uma forte redução do ritmo de crescimento do PIB real da economia brasileira, como se pode verificar no Figura 1. A perda de dinamismo econômico, na década de
1980 , fez com que a literatura especializada batizasse tal década como a "década perdida", dados as suas baixas taxas médias de crescimento econômico - especialmente se comparadas com as das décadas anteriores. Mal sabiam os analistas e economistas que viveram os anos 80 que a década seguinte seria ainda pior, em termos de crescimento do PIB real, conforme apontam os dados da tabela 1. Ademais, dados do IBGE revelam que, enquanto o PIB per capita, nos anos 70 , chegou a crescer pouco mais de $6 \%$ ao ano (média anual), nos anos 80 variou apenas cerca de $0,9 \%$ (ao ano, em média) e, nos anos 90, ficou em apenas cerca de $0,1 \%$ ao ano!! Esta comparação inicial entre indicadores dos anos 80 e os dos anos 90 já nos permite destacar algo que talvez poucos tenham percebido: nos anos 90, a economia brasileira cresceu ainda menos do que crescera na chamada "década perdida". 6

A década de 80 foi um período caracterizado por persistentes altas inflacionárias, que desestimularam os investimentos produtivos e promoveram fortes reduções dos salários médios reais de todos os setores da economia brasileira. O cenário econômico internacional do período explica, em grande

6. É impressionante constatar que seriam necessários cerca de 700 anos (!!) para que a renda per capita brasileira dobrasse (como quase chegou a ocorrer nos anos 70) caso a evolução deste indicador continue, nos próximos anos, no mesmo débil ritmo de crescimento apresentado nos anos 90 . 
Tabela 1. Taxas médias anuais de crescimento do PIB real (*) Brasil 1980-1999.

\begin{tabular}{|cc|cc|}
\hline \multicolumn{2}{|c|}{ Anos 80 } & \multicolumn{2}{c|}{ Anos 90 } \\
\hline 1980 & 9,2 & 1990 & $-4,3$ \\
\hline 1981 & $-4,5$ & 1991 & 0,3 \\
\hline 1982 & 0,5 & 1992 & $-0,8$ \\
\hline 1983 & $-3,5$ & 1993 & 4,2 \\
\hline 1984 & 5,3 & 1994 & 5,8 \\
\hline 1985 & 7,9 & 1995 & 4,2 \\
\hline 1986 & 7,6 & 1996 & 2,8 \\
\hline 1987 & 3,6 & 1997 & 3,7 \\
\hline 1988 & $-0,1$ & 1998 & 0,2 \\
\hline 1989 & 3,3 & 1999 & 0,8 \\
\hline $\begin{array}{l}\text { Taxa média } \\
\text { do período }\end{array}$ & $\mathbf{2 , 8 3}$ & $\begin{array}{l}\text { Taxa média } \\
\text { do período }\end{array}$ \\
\hline
\end{tabular}

Fonte: IBGE.

$\left(^{*}\right)$ variações percentuais anuais em relação ao ano anterior.

parte, os resultados decepcionantes da economia brasileira. A crise da dívida externa mexicana, deflagrada em setembro de 1982, fechou os canais de renovação dos empréstimos aos países endividados do terceiro mundo junto aos banqueiros privados. $\mathrm{O}$ Brasil teve de recorrer ao Fundo Monetário Internacional, no início da década, para "rolar" sua dívida externa, submetendo-se às suas metas "draconianas" de controle do desempenho de alguns indicadores macroeconômicos. Durante toda a década, houve remessas significativas de recursos ao exterior, reduzindo os raios de manobra da política econômica. A economia teve de conviver com as constantes necessidades de obter dólares para honrar sua crescente dívida externa, o que pressionava pela desvalorização real da taxa de câmbio. A economia indexou-se ao dólar e a inflação só pôde ser controlada em curtos momentos posteriores à adoção de diversos planos econômicos que não conseguiam deter uma cada vez mais breve volta da inflação e não logravam êxito na tentativa de desindexar a economia. Neste contexto, cada vez mais a recessão econômica constituía-se em mecanismo (explícito ou não) de obtenção de superávits na balança comercial brasileira, com o objetivo de obter os dólares para honrar o serviço da dívida externa ${ }^{7}$.

Estas foram as características gerais da década, mas é bom ressaltar que ela teve diferentes conjunturas. Houve um primeiro período, entre 1981 e 1983, marcado por forte recessão econômica e pelo fenômeno, até então pouco comum no Brasil, de aumento do desemprego. Os juros reais subiram expressivamente, levando a uma destacada mudança na taxa de investimento bruto da economia em relação ao PIB: em 1981, o investimento representava $24,3 \%$ do PIB e, em 1983, caiu para apenas $19,9 \%$, um dos resultados mais baixos da década. O governo Figueiredo encerrou-se melancolicamente e a crise social se alastrou pelo país. A inflação, em 1983, atingia o recorde (até então...) de 154,5\% ao ano.

O período entre 1984 e 1986 foi marcado por uma recuperação da atividade econômica brasileira. Esta recuperação foi deslanchada inicialmente por um fator externo: a forte recuperação da economia americana e a conseqüente ampliação de suas importações permitiram a diversos países do mundo (inclusive os europeus) ampliarem suas vendas aos EUA e adentrarem um ciclo de recuperação econômica. No caso da economia brasileira, os ajustamentos recessivos dos primeiros três anos da década e as duas maxidesvalorizações ocorridas em período recente (de dezembro de 1979 e a fevereiro de 1983) estimularam o setor industrial, em especial (mas também ao agropecuário e ao extrativista), apesar da taxa baixa de investimento ainda persistente em 1984 e 1985, a ampliar expressivamente suas vendas ao exterior. As exportações brasileiras saltaram de US\$ 20,2 bilhões, em 1983, para US\$ 27,0 bilhões em 1984.

As novas expectativas geradas pela posse do governo da Nova República e a adoção do Plano Cruzado, em fevereiro de 1986, deu novo impulso ao

7. Serviço da dívida externa: pagamento de juros mais amortizações da dívida externa. 
crescimento econômico brasileiro. O período de "bonança", contudo, durou pouco em função das dificuldades do governo em romper definitivamente com a indexação da economia e em enfrentar as restrições externas.

Mais ao final da década, entre 1987 e 1989, o cenário econômico foi marcado por forte instabilidade, alternando momentos em que parecia que a economia iria retomar uma trajetória ascendente com momentos em que eram fortes as reversões de expectativas, em especial por causa da exacerbação do ritmo de crescimento da inflação (em 1987 a inflação anual foi de $224,8 \%$, saltando para $684,5 \%$ em 1988 e para incríveis $1.320,0 \%$ em 1989 - o último ano de Sarney). A sucessão de planos econômicos do período, todos fracassados na tentativa de controlar a inflação e de eliminar os cada vez mais frágeis mecanismos de indexação da economia, acabou levando o Brasil à beira da hiperinflação.

\section{Anos 90: o fracasso de um novo "modelo"}

O ano de 1990 representou um marco na política econômica brasileira. Foi a partir deste ano que o Brasil passou a adotar políticas que se enquadram naquilo que a literatura econômica internacional convencionou chamar de Consenso de Washington, ou seja, um conjunto de políticas que visam promover a abertura comercial e financeira, privatizar as empresas públicas (quer sejam as estatais produtoras de bens ou as empresas geradoras de serviços públicos), desregulamentar os mercados de trabalho e enfatizar, como principal objetivo de política macroeconômica, o controle da inflação e dos indicadores fiscais, como forma de mostrar "bom comportamento" aos investidores externos e, assim, atrair (supostamente) crescentes aportes de investimentos estrangeiros.

A posse de Fernando Collor, em março de 1990, promoveu o início de um processo de abertura comercial e financeira da economia brasileira e de uma série de medidas de política econômica e de modificações no papel do Estado que nos permitem batizar a década como a "década do neoliberalismo". Depois de muitas décadas de derrotas eleitorais, o ideário liberal, talvez ajudado pelo 'ventos' que vinham da Inglaterra e dos EUA, finalmente conseguia se fazer implementar no cenário econômico brasileiro.

A alíquota média simples de importação reduziu-se à metade de seu valor de 1990 (quando era de cerca de $32 \%$ ) em apenas 3 anos, e chegou a cerca de um terço do seu valor de 1990 já em 1995 (Baumann et al., 1995). Esse processo de abertura comercial favoreceu a entrada de produtos importados na cesta de consumo dos brasileiros (de uma certa parcela da população, bem entendido) e também a compra de elevadas quantidades de máquinas e bens intermediários para abastecer as indústrias que operam no Brasil.

Não cabe aqui discutir minuciosamente as idas e vindas da política econômica dos Planos Collor I e II, apenas ressaltar que foi um período de recessão da atividade econômica e de rápida desestruturação de importantes elos da cadeia produtiva industrial. No final do curto mandato de Collor, a instabilidade política que marcou sua gestão intensificou as expectativas negativas decorrentes de sua própria figura política e da manutenção das medidas econômicas de restrição de expansão da demanda agregada, ampliando a recessão e desestimulando os investimentos produtivos. O breve período Itamar caracterizou-se pela continuidade do processo de abertura comercial, mas também por um afrouxamento das medidas recessivas que haviam norteado a política econômica do período Collor. O final do mandato de Itamar Franco foi dedicado à adoção de medidas de cunho fiscal e de ajustes para a implementação da nova moeda, o Real.

O fato mais marcante da década de 1990 foi, sem dúvida, a implementação do Plano Real. Também não cabe aqui, para os interesses a que se propõe este trabalho, detalhar as diversas fases pelas 
quais passaram a implementação e a execução do Plano Real ${ }^{8}$. Pretendemos apenas pontuar alguns de seus principais efeitos sobre o mercado de trabalho, emprego e produção industrial.

Conforme já comentamos acima, os anos 90 iniciaram-se com forte retração da atividade econômica, que começou a recuperar-se apenas em 1993. A partir de julho de 1994, com a implementação da nova moeda, com o controle da inflação e com a retomada da expansão do crédito ao consumo, a economia adentrou uma fase de recuperação econômica importante, mas que logo se reverteu. Houve nova retração das atividades econômicas a partir do segundo trimestre de 1995 até o final do primeiro trimestre de 1996, quando se fizeram sentir, na elaboração da política econômica do período (especialmente na ampliação das taxas de juros reais, para tentar estancar a sangria de dólares de nossas reservas; medidas como novos cortes no Orçamento, restrições do crédito ao consumo etc.), os efeitos da fuga de capitais ocorrida após a crise mexicana de final de 1994.

Com a aproximação das eleições de 1996, as primeiras após a implementação do Plano Real, e passados os principais efeitos negativos da crise mexicana nas expectativas dos investidores internacionais, o governo resolveu "afrouxar o cinto" e, a partir do segundo semestre de 1996, a economia mostrou novos sinais de recuperação. Entretanto, esta recuperação teve fôlego curto, pois a balança comercial, que acumulou portentosos déficits já a partir do final de 1996 e especialmente durante o ano de 1997, passou a gerar desconfiança dos agentes econômicos em relação à política cambial do governo brasileiro. Ficavam evidentes, pelos menos para os observadores mais lúcidos e menos comprometidos com o governo, que havia uma contradição quase insanável no modelo econômico representado pelo Plano Real, que opunha os objetivos de uma estabilização inflacionária fortemente baseada na abertura comercial aos anseios da sociedade de uma retomada sustentada do crescimento econômico. A excessiva valorização do câmbio no início do plano e a insistência em mantê-lo valorizado por mais de três anos depois da crise mexicana (que expôs a inevitável vulnerabilidade brasileira frente às chamadas "crises internacionais", as quais, diga-se de passagem, tornaram-se cada vez mais freqüentes ao longo da segunda metade da década) ampliaram expressivamente o endividamento externo brasileiro (dados os recorrentes e crescentes déficits em conta corrente) e também o custo e o estoque da dívida interna, dada a necessidade, cada mais angustiante para a economia como um todo (especialmente para o setor produtivo, evidentemente), de se manterem elevadas as taxas reais de juros, como forma de tentar "segurar" o dólar barato.

A partir de meados de 1997, com a chamada "crise asiática", o governo decidiu adotar novas medidas recessivas no âmbito fiscal e no monetário para tentar dissipar a crise sem precisar sancionar a pressão sobre o câmbio. A economia adentrava, então, um período muito difícil, em que ficavam praticamente insanáveis as contradições do modelo adotado pelo governo FHC e tornava-se cada vez mais desesperadoras as tentativas de controlar os desajustes do balanço de pagamentos brasileiro, sem, no entanto, conseguir dissipar a crise cambial e, depois, sem conseguir evitar a drástica desvalorização do Real ocorrida em janeiro de 1999.

Em termos de crescimento econômico, é sempre bom repetir, os resultados dos anos 90 foram decepcionantes, mesmo se comparados com os lamentáveis anos 80 . O período de auge da atividade econômica dos anos 90 foi mais curto e menos pronunciado do que havia sido o auge dos anos 80

8. Para tanto, poderíamos aqui sugerir inúmeros livros ou artigos, mas ficamos em duas sugestões que atenderiam muito bem aos interessados em estudar e compreender os condicionantes internacionais e internos da adoção do Plano Real e em realizar uma revisão de suas diferentes conjunturas. Trata-se do livro de Luís Filgueiras, intitulado "História do Plano Real"e do artigo de Batista Jr. (1996) (ver demais indicações na bibliografia). 
(rever tabela 1); ademais, o final da década de 1990 foi muito pior, em termos de crescimento da produção, do que havia sido o final (conturbado) do mandato de Sarney. Resta-nos, ainda, ressaltar outros aspectos dos resultados da "década da abertura comercial e financeira".

A participação das exportações brasileiras no total das exportações mundiais tem diminuído sistematicamente ao longo dos anos 90, revertendo os razoáveis resultados que haviam sido obtidos na década de 80 . Se considerarmos as exportações do Brasil em relação às exportações de países em desenvolvimento (contando ou não, entre esses países, aqueles que não são exportadores de petróleo), a constatação é igualmente decepcionante: nossas exportações têm crescido muito menos do que as desses países ao longo dos anos 90 (Batista Jr. 1996).

Estudo recente publicado pelo IEDI revela outros dados que retratam a forte deterioração da competitividade externa da indústria brasileira e alerta para a necessidade de elaboração de uma política industrial consistente, com um modelo de retomada do desenvolvimento econômico, como forma de tentar criar as condições estruturais para reverter este quadro de perda de competitividade externa de nossa indústria. Dados desse estudo apontam que diminuiu aceleradamente, ao longo dos anos 90, a parcela de nossas exportações que faz parte dos setores cuja demanda, no comércio mundial, tem se revelado crescente no período. Ao mesmo tempo, nossas importações têm sido maiores exatamente nos setores mais dinâmicos do comércio mundial, mostrando que precisamos urgentemente constituir um novo processo de "substituição de importações" como forma de evitar uma continuidade da deterioração de nosso saldo comercial no futuro.

\section{O COMPORTAMENTO DO EMPREGO INDUSTRIAL}

Como se observou anteriormente, ao contrário do que ocorreu, com maior ou menos ênfase, ao longo de todo o século XX, foi a partir dos anos 80 que a economia brasileira passou a ostentar baixo dinamismo econômico. Apesar do cenário de queda dos investimentos, de recessão econômica, de ampliação do endividamento externo e de altas inflacionárias cada vez mais expressivas, não ocorreu desestruturação da indústria brasileira, que parece ter se adaptado rapidamente ao cenário adverso que dificultava os negócios (inflação, juros altos, recessão, perda gradativa de capacidade do Estado em implementar políticas industriais etc.). A tabela 2 mostra que, entre 1982 e 1989, a participação do emprego industrial no conjunto das ocupações brasileiras manteve-se num patamar próximo dos $25 \%{ }^{10}$. Tal fato é surpreendente em especial se levarmos em conta que, apesar dos pesares, o conjunto da ocupação cresceu, entre 1982 e 1989, em cerca de 3,6\% ao ano (conforme se depreende da tabela) ${ }^{11}$.

$\mathrm{O}$ efeito mais deletério da crise dos anos 80 sobre o mercado de trabalho brasileiro fez-se sentir pela evolução dos salários e pela deterioração do perfil distributivo brasileiro, além da precarização e ampliação da informalidade das ocupações, conforme já apontamos em outro estudo (Jannuzzi et al., 1995). A ampliação do peso de ocupações caracterizadas por rendimentos do trabalho mais baixos do que a média (notadamente o emprego assalariado sem carteira assinada e também diversas formas de trabalho autônomo de mão-de-obra de baixa qualificação) promoveu a piora do perfil distributivo brasileiro nos anos 80, agravando um problema já crônico da sociedade brasileira - sua elevada desigualdade.

9. O estudo não fala nestes termos.

10. Os dados da mesma tabela mostram que a participação do emprego industrial no conjunto dos ocupados da economia brasileira passaria a se reduzir apenas a partir de 1990 .

11. Foram criados, entre 1982 e 1989, pouco mais de 1 milhão de postos de trabalho somente na indústria de transformação situada nas seis principais regiões metropolitanas brasileiras. 
Tabela 2. Evolução da população ocupada na indústria de transformação.

Total das regiões metropolitanas brasileiras 1982-2001.

\begin{tabular}{|c|c|c|c|}
\hline $\begin{array}{c}\text { Ano } \\
\left({ }^{*}\right.\end{array}$ & $\begin{array}{c}\text { Total } \\
(\mathbf{1})\end{array}$ & $\begin{array}{c}\text { Indústria } \\
(\mathbf{2})\end{array}$ & $\begin{array}{c}\text { Participação } \\
(\mathbf{3})\end{array}$ \\
\hline 1982 & 12978980 & 3203889 & 24,7 \\
\hline 1983 & 12909626 & 3060424 & 23,7 \\
\hline 1984 & 13578398 & 3163637 & 23,3 \\
\hline 1985 & 14013792 & 3397113 & 24,2 \\
\hline 1986 & 15092358 & 3937539 & 26,1 \\
\hline 1987 & 15382462 & 3894784 & 25,3 \\
\hline 1988 & 16178344 & 4061678 & 25,1 \\
\hline 1989 & 16625606 & 4204916 & 25,3 \\
\hline 1990 & 17203869 & 4118113 & 23,9 \\
\hline 1991 & 15208516 & 3454310 & 22,7 \\
\hline 1992 & 15085207 & 3126523 & 20,7 \\
\hline 1993 & 15316858 & 3142141 & 20,5 \\
\hline 1994 & 15691779 & 3081624 & 19,6 \\
\hline 1995 & 16051447 & 3082562 & 19,2 \\
\hline 1996 & 16464757 & 3088593 & 18,8 \\
\hline 1997 & 16391292 & 2834562 & 17,3 \\
\hline 1998 & 16454640 & 2717162 & 16,5 \\
\hline 1999 & 16346074 & 2657605 & 16,3 \\
\hline 2000 & 17274058 & 2815944 & 16,3 \\
\hline 2001 & 17258281 & 2803158 & 16,2 \\
\hline & & & \\
\hline
\end{tabular}

Fonte: IPEADATA. Elaboração própria. Dados do IBGE (PME).

$\left({ }^{*}\right)$ dados referem-se aos respectivos meses de agosto de cada ano selecionado.

As informações computam o número total de pessoas com 15 ou mais anos de idade.

Notas: (1)representa o conjunto de ocupados nas regiões metropolitanas de Recife, Salvador, Belo Horizonte, Rio de Janeiro, São Paulo e Porto Alegre; (2) representa o conjunto de ocupados na indústria de transformação nas RM's citadas; (3) parcela da ocupação industrial no conjunto dos ocupados (em \%).

Nos anos 90, além do baixo desempenho da taxa média de crescimento do PIB real e dos resultados decepcionantes de nossas exportações, o que chama a atenção são os resultados da taxa de desemprego ao longo da década. A abertura comercial iniciada com Collor, e aprofundada por FHC em seu primeiro mandato, ao lado, neste último caso, de um longo período de acentuada valorização cambial, promoveram uma significativa expansão das importações, com efeitos perversos sobre a produção e o emprego industriais. A Figura 2 mostra que o valor das importações mais que triplicou entre 1990 e 1997, mantendo-se, ainda depois de 1997, em patamares elevados. A taxa de desemprego quase triplicou ao longo da década. A produção industrial teve queda importante na recessão do Plano Collor e depois apresentou uma leve recuperação, mas encerrou a década com resultados apenas pouco superiores aos observados no início do período. $\mathrm{O}$ emprego industrial caiu quase continuamente ao longo dos anos 90. As curvas do figura sugerem que a ampliação das importações (devida à redução das alíquotas de importação desde o início da década e à valorização cambial após 1994) está bastante relacionada com a vertiginosa expansão do desemprego ao longo da década - que chegou a mais do que dobrar, no final dos anos 90, a taxa que estivera vigente em 1989.

Além da abertura e do câmbio valorizado, é evidente que a retração da atividade econômica devido, especialmente, à forte vulnerabilidade externa em que se viu colocada a economia brasileira pela política macroeconômica -, e os juros internos elevadíssimos (durante muitos anos, os mais elevados do mundo!!) também contribuíram para o aumento do desemprego.

A retração do emprego industrial foi maior do que a retração do emprego em outros setores, resultando em redução do peso relativo do emprego industrial no conjunto da ocupação. Esse foi um fenômeno ocorrido em todo o país, mas foi mais pronunciado ainda na região Sudeste, conforme apontam os dados da tabela 3. Essa retração do emprego industrial rebateu-se sobre diversas ocupações - qualificadas ou não - e veio acompanhada de redução expressiva nos rendimentos das ocupações da indústria, não poupando, inclusive, os Profissionais da Informação, questão tratada em seguida. 


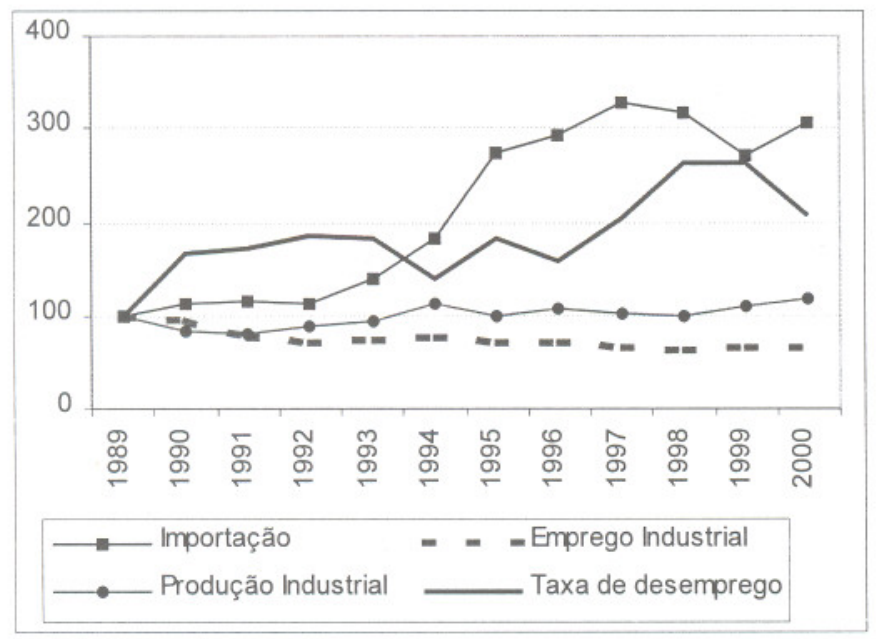

Figura 2. Evolução de Indicadores econômicos Brasil 1989-2000 (Número Índice).

\section{A EVOLUÇÃO DO MERCADO DE TRABALHO DOS PROFISSIONAIS DA INFORMAÇÃO}

Como mostrado na seção anterior, a dinâmica econômica nas duas últimas décadas foi progressivamente desfavorável à expansão do emprego, sobretudo o industrial, ainda que com alguns curtos interregnos pró-cíclicos. Em um contexto de baixo crescimento econômico, de falta de dinamismo industrial e fragilização das relações de trabalho, as possibilidades de inserção ocupacional, de preservação do posto de trabalho e de mobilidade de carreira vieram a diminuir para a maioria da população ocupada brasileira, não poupando inclusive os
Knowledge workers. É o que se mostra nesta parte do trabalho.

Mais especificamente, discute-se aqui a evolução do mercado de trabalho de uma parcela significativa destes trabalhadores do Conhecimento - os Profissionais da Informação - ao longo das duas últimas décadas. Para tanto, faz-se uso de parte dos resultados tabulados em Jannuzzi (2001), onde são trazidos dados sobre volume quantitativo da mão de obra ocupada, sobre o rendimento e status socioeconômico de cerca de 350 ocupações, na forma levantada nos Censos Demográficos de 1980 e 1991 e nas Pesquisas Nacionais por Amostra de Domicílios realizadas nos anos $90^{12}$.

Tabela 3. Participação do setor industrial no total de ocupados de cada região.

\begin{tabular}{|l|r|r|r|r|r|r|r|}
\hline \multicolumn{1}{|c|}{ Brasil/ 1992 - 1999 } \\
\hline \multicolumn{1}{|c|}{ Região } & $\mathbf{1 9 9 2}$ & $\mathbf{1 9 9 3}$ & $\mathbf{1 9 9 5}$ & $\mathbf{1 9 9 6}$ & $\mathbf{1 9 9 7}$ & $\mathbf{1 9 9 8}$ & $\mathbf{1 9 9 9}$ \\
\hline Centro-Oeste & 7,1 & 6,7 & $\mathbf{7 , 7}$ & $\mathbf{7 , 9}$ & 8,6 & 7,4 & 7,3 \\
\hline Nordeste & 8,0 & 7,6 & 7,0 & 7,3 & 7,2 & 6,8 & 6,9 \\
\hline Norte & 9,8 & 10,0 & 10,1 & 10,0 & 10,5 & 8,8 & 8,6 \\
\hline Sudeste & 16,9 & 17,0 & 15,9 & 15,8 & 15,3 & 14,9 & 14,4 \\
\hline Sul & 15,8 & 16,2 & 15,8 & 15,7 & 16,0 & 15,5 & 15,7 \\
\hline
\end{tabular}

Fonte: IBGE. PNAD (microdados). Apud IPEA (2001).

12. Empregou-se também a Contagem Populacional de 1996, com correção de subenumeração de população, para se chegar às estimativas de população ocupada por grupos ocupacionais em 1996 (vide Jannuzzi, 2001). 
Para este trabalho, foram selecionadas as ocupações de Bibliotecários, Arquivistas, Museólogos, Analistas de Sistemas, Estatísticos, Economistas, Sociólogos, Professores Universitários, Jornalistas e Escritores como grupos representativos do que têm se convencionado chamar de Profissionais da Informação, em um sentido mais abrangente. Para garantir maior consistência dos dados (pela diminuição do erro amostral e de registro de informação em campo), estas ocupações foram reunidas em quatro grupos, de acordo com a similaridade das atividades desenvolvidas. Ainda que não se possa garantir que os indivíduos que desempenham estas funções estejam efetivamente envolvidos diretamente na produção, tratamento, análise ou disseminação de pacotes informacionais para o setor produtivo como requerido por Ponjuán Dante (2000) para classificá-los como pertencentes ao conjunto dos Profissionais da Informação -, pareceu-nos que a operacionalização proposta é uma aproximação pragmática e consistente para os objetivos do trabalho, tendo em vista as limitações das fontes de dados que se pretendeu privilegiar.

Uma dessas limitações é que pelas rotinas de codificação da informação sobre ocupação nas pesquisas referidas, não é possível resgatar algumas das novas profissões ligadas ao desenvolvimento da Internet e Telecomunicações. Estas ocupações têm sido registradas de forma agregada juntamente com outras menos conhecidas ou mal definidas, que passaram a representar parcela crescente e não meramente residual nas pesquisas.Vale observar também que se está considerando neste artigo o conjunto de indivíduos que trabalham 40 ou mais horas por semana, que constituem parcela majoritária da força de trabalho ocupada (mais de $75 \%$ ) no país. Além disso, as cifras aqui apresentadas devem ser entendidas como estimativas amostrais e não resultantes de um processo de enumeração exaustivo junto à população ou a órgãos de classe ${ }^{13}$. Por fim, há que ser lembrado que as informações aqui tabuladas resultam da declaração direta dos indivíduos (ou de seus familiares), não das empresas em que trabalham (onde, em tese, se poderia coletar informações mais precisas sobre o cargo ou profissão exercida). Assim, um analista de sistemas que se declare na pesquisa como gerente ou diretor de empresa não estará sendo contabilizado como um Profissional da Informação, ainda que possa desempenhar atividades típicas do mesmo. Por outro lado, um economista não envolvido com análise de mercado (consumidor ou financeiro) ou qualquer outra atividade de pesquisa, assim como uma auxiliar de biblioteca que se declare como bibliotecária estariam contemplados no grupo.

Há certamente outras formas de empreender uma análise da evolução do mercado de trabalho destes profissionais, como mostra a coletânea de textos apresentada por Valentim (2000). Vale observar, contudo, que, em geral, as análises disponíveis resultam de pesquisas diretas com amostras pequenas de profissionais, escolhidas de forma intencional ou não probabilística, ou de informações coletadas junto a conselhos de classe. Ainda que muito interessantes e ricas em informações qualitativas, estas análises não podem ter seus resultados facilmente extrapolados para o universo de profissionais no mercado. No caso específico deste artigo, a escolha das fontes de dados apontadas justifica-se não apenas pela cobertura de um período importante para a análise da temática, pela representatividade amostral dos seus resultados, pela abrangência espacial de referência, como pelocaráter um tanto inédito do uso das mesmas para estudo da inserção ocupacional das categorias profissionais listadas.

13. Vale lembrar que as informações sobre características da mão-de-obra são levantadas no questionário da amostra do Censo Demográfico, não no questionário básico aplicado à totalidade dos domicílios brasileiros. 


\section{EMPREGO DOS PROFISSIONAIS \\ DA INFORMAÇÃO NO BRASIL: EVOLUÇÃO E CARACTERÍSTICAS}

Ao longo dos últimos vinte anos, ou mais precisamente entre 1980 e 1996, o número de pessoas ocupadas, com idade dentre 15 e 64 anos, com jornada de trabalho de 40 ou mais horas, aumentou quase $47 \%$. Em termos médios anuais, a população ocupada aumentou em 2,4\% nesses 16 anos, cifra essa abaixo do necessário para atender a demanda anual por novas ocupações, em função, sobretudo, do ingresso de jovens e mulheres no mercado de trabalho. Esse descompasso entre oferta e demanda, ocasionou, como já se observou, um aumento da população em situação de desemprego no país, em especial nos anos 90 .

Sob a perspectiva de todo o conjunto, o comportamento do mercado de trabalho dos Profissionais da Informação foi comparativamente melhor, já que, entre 1980 e 1996, houve um crescimento de cerca de $82 \%$ de pessoal ocupado em postos de trabalho dessa natureza (Tabela 4). Analisando as ocupações separadamente, verifica-se que este elevado crescimento deve-se à forte demanda por Analistas de Sistemas e Estatísticos no período, em especial na década de 80 , quando este grupo de profissionais aumentou em $11 \%$ ao ano. É curioso observar que, na década de 90 , quando a chamada
"Revolução do Microprocessador" se intensificou ainda mais, o ritmo de crescimento destas profissões se arrefecesse de forma tão significativa. Como revelam os dados da tabela 4, a taxa média anual de crescimento desses profissionais passou para $4 \%$ ao ano entre 1991 e 1996. Parodiando German, citado há pouco: nem mesmo os profissionais que lidam com processos automatizados de armazenamento ou sumarização de informação estruturada estão protegidos contra a racionalização de processos que eles mesmos ajudam a implementar.

As demais categorias de Profissionais da Informação cresceram a taxas próximas ou mais baixas que a média do total de ocupações brasileiras ao longo do período, como a de Bibliotecários, Arquivistas e Museólogos. A julgar pelas estimativas fornecidas pelas pesquisas aqui consideradas, este grupo teve um aumento líquido (entradas subtraídas das saídas) de apenas 2 mil pessoas em postos de trabalho em tempo integral (oito horas diárias) ao longo dos 16 anos em análise. O grupo de Jornalistas e Escritores expandiu-se de forma mais expressiva no período, ainda que no primeiro quinqüênio da década de 1990 viessem a apresentar uma pequena redução quantitativa (-1,4 \% ao ano). Já o grupo dos Analistas socioeconômicos e Professores Universitários teve um comportamento pior nos anos 80 , vindo a se expandir mais rapidamente na década passada ( $5 \%$ ao ano).

Tabela 4. Total de pessoal ocupado com 15 a 64 anos e jornada de 40 ou mais horas em ocupações selecionadas.

\begin{tabular}{|c|c|c|c|c|c|c|}
\hline \multicolumn{7}{|c|}{ Brasil 1980 - 1996} \\
\hline Categorias profissionais & 1980 & 1991 & 1996 & $\begin{array}{c}\text { Variação } \\
\text { média anual } \\
(\%) 1991-80\end{array}$ & $\begin{array}{c}\text { Variação } \\
\text { média anual } \\
(\%) 1996-91\end{array}$ & $\begin{array}{c}\text { Variação } \\
\% \\
1996-80\end{array}$ \\
\hline Bibliotecários, arquivistas, museólogos & 10.047 & 11.601 & 12.039 & 1,3 & 0,7 & 19,8 \\
\hline Analistas de sistemas e estatísticos & 18.609 & 60.025 & 72.850 & 11,2 & 3,9 & 291,5 \\
\hline Analistas socioecon e prof. Universitários & 65.027 & 74.430 & 94.243 & 1,2 & 4,8 & 44,9 \\
\hline Jornalistas e Escritores & 20.205 & 30.015 & 27.952 & 3,7 & $-1,4$ & 38,3 \\
\hline Total - profissionais da informação & 113.888 & 176.071 & 207.084 & 4,0 & 3,3 & 81,8 \\
\hline Total de pessoal ocupado & 31.716 .439 & 41.062 .537 & 46.494 .507 & 2,4 & 2,5 & 46,5 \\
\hline
\end{tabular}

Fonte: Censos demográficos 1980 e 1991, PNAD 92-99. 
Assim, como mostram essas evidências empíricas, a oferta de postos de trabalho para as ocupações típicas que lidam diretamente com a Informação - no seu armazenamento, catalogação, recuperação, sumarização, análise ou disseminação - foi significativamente distinta entre si. Entre 1980 e 1996, somente os Analistas de Sistemas ${ }^{14}$ tiveram crescimento acima da média das ocupações brasilei- ras. Os grupos de Analistas Socioeconômicos e de Jornalistas apresentaram um aumento inferior, mas relativamente próximo à média das ocupações. Entre os Bibliotecários a expansão foi bem mais baixa.

Como resultado desse comportamento diferenciado com relação à expansão do pessoal ocupado nos diversos grupos de Profissionais da Informação, as características típicas da mão de obra também

Tabela 5. Distribuição por sexo e grupos etários do pessoal ocupado com 15 a 64 anos e jornada de 40 ou mais horas em ocupações selecionadas.

\begin{tabular}{|c|c|c|c|c|c|}
\hline \multicolumn{6}{|c|}{ Brasil 1980 - 1996} \\
\hline Categorias profissionais & Sexo e grupo & 1980 & 1991 & 1996 & Variação \\
\hline \multirow{7}{*}{ Bibliotecários, arquivistas, museólogos } & Homens & 10,7 & 12,2 & 7,8 & $-2,9$ \\
\hline & Mulheres & 89,3 & 87,8 & 92,2 & 2,9 \\
\hline & Total & 100,0 & 100,0 & 100,0 & - \\
\hline & 15 a 29 anos & 46,5 & 25,8 & 21,2 & $-25,3$ \\
\hline & 30 a 49 anos & 43,9 & 63,9 & 65,6 & 21,7 \\
\hline & 50 a 64 anos & 9,6 & 10,2 & 13,2 & 3,6 \\
\hline & Total & 100,0 & 100,0 & 100,0 & - \\
\hline \multirow{7}{*}{ Analistas de sistemas e estatísticos } & Homens & 82,4 & 75,1 & 77,2 & $-5,2$ \\
\hline & Mulheres & 17,6 & 24,9 & 22,8 & 5,2 \\
\hline & Total & 100,0 & 100,0 & 100,0 & - \\
\hline & 15 a 29 anos & 44,7 & 40,8 & 33,4 & $-11,3$ \\
\hline & 30 a 49 anos & 51,2 & 56,6 & 62,7 & 11,5 \\
\hline & 50 a 64 anos & 4,1 & 2,6 & 3,9 & $-0,2$ \\
\hline & Total & 100,0 & 100,0 & 100,0 & $\cdot$ \\
\hline \multirow{7}{*}{$\begin{array}{l}\text { Analistas socioecon e } \\
\text { prof. Universitários }\end{array}$} & Homens & 70,5 & 61,3 & 60,6 & $-9,9$ \\
\hline & Mulheres & 29,5 & 38,7 & 39,4 & 9,9 \\
\hline & Total & 100,0 & 100,0 & 100,0 & - \\
\hline & 15 a 29 anos & 26,2 & 10,5 & 15,4 & $-10,8$ \\
\hline & 30 a 49 anos & 64,3 & 72,7 & 67,7 & 3,4 \\
\hline & 50 a 64 anos & 9,5 & 16,8 & 16,9 & 7,4 \\
\hline & Total & 100,0 & 100,0 & 100,0 & - \\
\hline \multirow{7}{*}{ Jornalistas e Escritores } & Homens & 79,1 & 64,9 & 53,7 & $-25,4$ \\
\hline & Mulheres & 20,9 & 35,1 & 46,3 & 25,4 \\
\hline & Total & 100,0 & 100,0 & 100,0 & - \\
\hline & 15 a 29 anos & 39,9 & 37,2 & 36,5 & $-3,4$ \\
\hline & 30 a 49 anos & 49,1 & 52,8 & 56,2 & 7,1 \\
\hline & 50 a 64 anos & 11,0 & 10,0 & 7,3 & $-3,7$ \\
\hline & Total & 100,0 & 100,0 & 100,0 & - \\
\hline
\end{tabular}

Fonte: Censos demográficos 1980 e 1991, PNAD 92-99.

14. Para simplicidade da redação se adota, deste ponto em diante, a denominação do primeiro sub-grupo de profissionais para designar cada um dos grupos ocupacionais de Profissionais da Informação. 
apresentaram mudanças específicas. A baixa expansão do grupo de Bibliotecários, por exemplo, pode explicar o acentuado envelhecimento da mão de obra aí alocada durante o período (tabela 5). Em 1980, $44 \%$ dos indivíduos deste grupo tinham entre 30 e 49 anos, cifra esta que passou a quase dois terços em 1996. Profissionais com idade entre 15 a 29 anos tiveram sua participação reduzida de $47 \%$ para $21 \%$ no período. Tivesse sido maior a oferta de postos de trabalho na área, teriam ingressado mais jovens, além de, certamente, mais homens. Em 1996, a larga maioria dos ocupados deste setor ainda eram mulheres (92\%).

Nos demais grupos de Profissionais, observa-se também um envelhecimento da mão de obra ocupada, mas menos intenso em função do desempenho na absorção de jovens ao longo das décadas passadas. O que é interessante observar é que tal fato favoreceu também um aumento da participação feminina, sobretudo entre os Jornalistas e Escritores. Assim, pelas estimativas de 1996, este grupo teria $46 \%$ de mulheres, mais do que o dobro da parcela identificada em 1980 (21\%). Entre os Analistas Socioeconômicos, a participação da mulher atingia, em 1996, cerca de 40\%. É entre os Analistas de Sistemas que a presença da mulher é a menor $(22 \%$ em 1996).

\section{RENDIMENTO, GRAU DE FORMALIZAÇÃO E STATUS SOCIOECONÔMICO NO PERÍODO}

Como observado anteriormente, o rendimento do trabalho das pessoas ocupadas seguiu as oscilações cíclicas da economia brasileira nas últimas décadas. Assim, como era de se esperar em função da conjuntura recessiva induzida pelo Plano Collor, o rendimento médio em 1991 apresentou forte queda em relação ao verificado em 1980, recuperando parte de seu poder aquisitivo a partir de 1993. Tal recuperação não foi suficiente, contudo, para restabelecer o poder de compra dos salários identificado em 1980. Como se pode verificar na tabela 6 , a queda de $23 \%$ dos rendimentos do pessoal ocupado entre 1980 e
1991 foi acompanhada de uma elevação de apenas $10 \%$ entre 1991 e 1996.

É importante observar que todas as quatro categorias de Profissionais da Informação apresentaram uma queda real do rendimento médio dos ocupados mais expressiva que a média de todos ocupados no país entre 1980 e 1996 . Bibliotecários, Analistas Socioeconômicos e Jornalistas tiveram uma queda real de mais de $20 \%$ do rendimento médio do trabalho nesse período, perda acima dos $16 \%$ verificado entre toda a população ocupada no Brasil. No caso dos Analistas de Sistemas a queda do nível salarial foi ainda mais acentuada (diminuição de $44 \%$ do rendimento médio entre 1980 e 1996). Nos anos 80, em que a expansão da oferta de empregos para estes profissionais foi, como já se apontou, muito acentuada, a queda no nível médio de rendimento chegou quase a $50 \%$, isto é, o rendimento médio caiu de um nível próximo de $\mathrm{R} \$ 3.600$ para cerca de R \$ 1.800 .

Com isso, os diferenciais médios de rendimentos entre os grupos ocupacionais acabou diminuindo: em 1980, os Analistas de Sistemas, grupo de maior rendimento médio naquele momento, recebiam cerca de 3,5 vezes o rendimento médio dos Bibliotecários; em 1996, os Analistas Socioeconômicos, que passaram a dividir a liderança do nível de rendimento com os Analistas de Sistemas, ganhavam 2,8 vezes o rendimento dos Bibliotecários. Vale acrescentar que, em que pese estes diferenciais, os Profissionais da Informação recebem uma remuneração cerca de 2 a 5 vezes a média dos ocupados no país.

Como se vê por estes resultados, a retribuição monetária conferida pelo mercado empregador e, em sentido mais geral, a valoração atribuída pela economia brasileira aos profissionais que lidam com a Informação, não têm sido maior que a garantida para a média dos ocupados no país.

Não foi apenas poder aquisitivo que os Profissionais da Informação viriam a perder entre 1980 e 1996. Alguns grupos, como os Jornalistas e em me- 
Tabela 6. Rendimento médio de pessoal ocupado com 15 a 64 anos e jornada de 40 ou mais horas em ocupações selecionadas.

\begin{tabular}{|c|c|c|c|c|c|c|}
\hline \multicolumn{7}{|c|}{ Brasil 1980 - 1996} \\
\hline Categorias profissionais & 1980 & 1991 & 1996 & $\begin{array}{c}\text { Variação } \\
(\%) 1991-80\end{array}$ & $\begin{array}{c}\text { Variação } \\
(\%) 1996-91\end{array}$ & $\begin{array}{c}\text { Variação \% } \\
1996-80\end{array}$ \\
\hline Bibliotecários, arquivistas, museólogos & 1.011 & 712 & 737 & $-29,6$ & 3,5 & $-27,1$ \\
\hline Analistas de sistemas e estatísticos & 3.574 & 1.819 & 2.000 & $-49,1$ & 10,0 & $-44,0$ \\
\hline Analistas socioecon e prof. universitários & 2.578 & 1.890 & 2.041 & $-26,7$ & 8,0 & $-20,8$ \\
\hline Jornalistas e Escritores & 1.596 & 1.046 & 1.200 & $-34,5$ & 14,7 & $-24,8$ \\
\hline Total - profissionais da informação & 2428 & 1644 & 1837 & $-32,3$ & 11,7 & $-24,3$ \\
\hline Total de pessoal ocupado & 446 & 342 & 376 & $-23,3$ & 9,9 & $-15,7$ \\
\hline
\end{tabular}

Fonte: Censos demográficos 1980 e 1991, PNAD 92-99.

Nota: valores monetários em reais de setembro de 1999.

nor medida os Analistas de Sistemas, passariam a apresentar níveis decrescentes de formalização no mercado de trabalho. Entre os primeiros - Jornalistas -, a parcela de contribuintes para a Previdência Pública, indicador básico de proteção social - na medida que confere ao ocupado o acesso ao seguro contra acidentes de trabalho, auxílio-doença, aposentadoria etc. -, apresentou uma queda significativa no período (quase 16 pontos percentuais) (tabela 7). Este resultado pode estar retratando um aumento de forma de inserção profissional mais precárias como a de assalariado sem carteira ou de autônomo (free lancer). Para os demais grupos a queda foi menor, sobretudo entre os Bibliotecários, certamente pela importância do emprego público e da menor oferta de postos no período, conforme assinalado. De qualquer forma, todos estes grupos não só gozam de níveis de proteção social muito superiores aos dos demais trabalhadores brasileiros, como também parecem ter sido mais bem sucedidos em preservá-los nas últimas décadas. Aparentemente, embora tenham perdido mais em termos salariais que o conjunto dos trabalhadores brasileiros, os Profissionais da Informação conseguiram preservar melhor seus direitos básicos de proteção social nas relações de trabalho.

Ao contrário do que se poderia inferir pelos resultados acima, os Profissionais da Informação não desfrutam de uma posição de menor prestígio hoje em relação ao passado. O que se coloca é que eles não estão muito mais valorizados do que já foram, em uma perspectiva relativa a outros grupos ocupacionais, como parecem defender algumas análises. Esta assertiva por ser atestada pela estabili-

Tabela 7. Proporção de contribuintes para Previdência Pública do pessoal ocupado com 15 a 64 anos e jornada de 40 ou mais horas em ocupações selecionadas.

\begin{tabular}{|l|c|c|c|c|}
\hline \multicolumn{7}{|c|}{ Brasil 1980 - 1996 } & \multicolumn{1}{c|}{ Variação } \\
\hline \multicolumn{1}{|c|}{ Categorias profissionais } & $\mathbf{1 9 8 0}$ & $\mathbf{1 9 9 1}$ & $\mathbf{1 9 9 6}$ & $\mathbf{1 9 9 6 - 8 0}$ \\
\hline Bibliotecários, arquivistas, museólogos & 95,2 & 92,6 & 95,1 & $-0,1$ \\
\hline Analistas de sistemas e estatísticos & 99,0 & 96,1 & 91,8 & $-7,2$ \\
\hline Analistas socioecon e prof. universitários & 97,5 & 95,4 & 93,6 & $-3,9$ \\
\hline Jornalistas e Escritores & 92,5 & 84,7 & 76,7 & $-15,8$ \\
\hline
\end{tabular}

Fonte: Censos demográficos 1980 e 1991, PNAD 92-99. 
dade do status médio dos grupos ocupacionais de profissionais de Informação no Brasil no período em análise $^{15}$ (tabela 8).

Como se pode verificar, há uma quase estabilidade do status dos grupos de Profissionais da Informação no período. Pode-se até mesmo apontar um pequeno avanço do status dos Analistas Socioeconômicos e Analistas de Sistemas, motivado talvez pelo aumento da escolaridade média destes profissionais (pelo engajamento crescente em cursos de pós-graduação). $\mathrm{O}$ aumento mais significativo do status de outras ocupações de nível superior, como a de Médicos, Engenheiros ou Magistrados, talvez seja indicativo de que as ocupações clássicas e necessárias ao atendimento dos serviços sociais básicos ainda sejam as mais bem valoradas e demandadas pela sociedade (e economia) nacional.

\section{PROFISSIONAIS DA INFORMAÇÃO NA INDÚSTRIA E OUTROS SETORES}

Os setores de atividade econômica que mais empregam Profissionais da Informação são os Serviços, os Serviços Sociais e os sub-setores mais dinâmicos da Indústria. Naturalmente, cada grupo ocupacional guarda certa especificidade em sua inserção econômica setorial, característica esta que tem se mostrado cada vez mais evidente (Tabela 9).

Os Bibliotecários têm uma presença marcante nos Serviços Sociais, setor no qual estão englobadas as universidades, escolas, hospitais e todas demais atividades na área de Educação e Saúde. Ao longo das últimas décadas tem aumentado a participação destes profissionais neste setor, a ponto de, em 1996, os Serviços Sociais concentrarem cerca de três de cada quatro Bibliotecários no país. A presença de

Tabela 8. Status médio de pessoal ocupado com 15 a 64 anos e jornada de 40 ou mais horas em ocupações selecionadas.

\begin{tabular}{|l|c|c|c|c|}
\hline \multicolumn{2}{|c|}{ Brasil 1980 - 1996 } & & \multicolumn{2}{c|}{ Variação } \\
$\mathbf{1}$ & & & $\mathbf{1 9 9 6}-\mathbf{8 0}$ \\
\hline Categorias profissionais & $\mathbf{1 9 8 0}$ & $\mathbf{1 9 9 1}$ & $9 \mathbf{6 1}$ & $-0,1$ \\
\hline Bibliotecários, arquivistas, museólogos & 93,1 & 94,3 & 93,0 & 1,1 \\
\hline Analistas de sistemas e estatísticos & 97,8 & 98,9 & 98,9 & 1,5 \\
\hline Analistas socioecon e prof. universitários & 97,6 & 99,2 & 99,1 & 0,8 \\
\hline Jornalistas e Escritores & 96,2 & 97,2 & 97,0 & 1,8 \\
\hline Magistrados e Procuradores & 98,1 & 99,9 & 99,9 & 1,8 \\
\hline Médicos e Dentistas & 97,6 & 99,4 & 99,4 & 1,7 \\
\hline Engenheiros e Arquitetos & 98,0 & 99,6 & 99,7 & \\
\hline
\end{tabular}

Fonte: Censos demográficos 1980 e 1991, PNAD 92-99.

15. O status socioeconômico de uma ocupação corresponde ao prestígio social conferido pela população às ocupações ou como a posição relativa da ocupação em um ranking classificatório das mesmas, ordenado por algum indicador socioeconômico simples ou composto, como rendimento auferido, nível de qualificação típico das ocupações, escolaridade da mão de obra nelas alocada ou mesmo uma combinação destas dimensões. Nesta perspectiva, por exemplo, Médico, Magistrado, Professor seriam consideradas ocupações de maior status que as de Trabalhador Rural, Pedreiro ou Empregado Doméstico já que na percepção subjetiva da sociedade seriam dotadas de maior prestígio social, assim como também apresentam indicadores objetivos de rendimento e escolaridade mais elevados. A medida de status apresentada corresponde a um índice de posição relativa da ocupação em um intervalo de 0 a 100, computada em Jannuzzi (2001). Mais precisamente, o índice socioeconômico posicional corresponde à porcentagem de indivíduos ocupados cujos níveis médios combinados de rendimento e escolaridade são menores ou iguais que os da ocupação considerada. Assim, um status de $93 \%$ para uma determinada ocupação - como é o caso do grupo dos Bibliotecários em 1996 - significa que o conjunto de trabalhadores aí classificados apresenta um nível médio combinado de rendimento e escolaridade superior a $93 \%$ da população ocupada. 
Bibliotecários na Indústria, moderna ou tradicio$\mathrm{nal}^{16}$, é residual e tem apresentado uma tendência declinante. $\mathrm{O}$ mesmo se pode dizer acerca da inserção dos mesmos nos Serviços em geral, que reúne desde a Prestação de Serviços Pessoais aos Serviços Financeiros, de Informática e de consultoria empresarial.

São nestes últimos sub-setores mais dinâmicos dos Serviços onde se concentram, cada vez mais, os Analistas de Sistemas. Em 1980, 26\% destes profissionais estavam nos Serviços, cifra esta que passou, em 1996, para 39\%. A necessidade de lidar com um volume crescente de informações em intervalos de tempo cada vez mais curtos, especialmente em atividades bancárias e financeiras, é certamente um dos fatores motivadores para a contratação destes profissionais. A terceirização de serviços de processamento de dados por parte de outras empresas (no comércio, indústria, etc) é outro fator que pode explicar esta concentração setorial desses profissionais. Por fim, a forte expansão dos serviços de teleinformática (Internet, etc) acabou criando novas oportunidades de inserção profissional no setor. A participação de Analistas de Sistemas na Indústria já foi mais importante no passado ( $25 \%$ no total dos sub-setores moderno e tradicional). A perda desses profissionais na Indústria Moderna deve estar relacionada não apenas à terceirização das atividades de processamento de dados nas empresas, como também pela dificuldade crescente que a indústria de hardware e software nacional passou a enfrentar com o fim das salvaguardas e proteção garantida pela Política nacional de Informática nos anos 90.

Pela importância numérica dos professores universitários, é natural que se encontrasse os Analistas Socioeconômicos concentrados nos Serviços Sociais (67\% em 1996). Tal como apontado para os Analistas de Sistemas, a participação dos Analistas Socioecônomicos tem sido declinante na Indústria. O curioso é que não se observa aumento correspon- dente nos Serviços. Estaria o setor produtivo contratando serviços de consultoria nas universidades e centros de pesquisa? Há claras evidências neste sentido, o que é muito positivo. O que parece surpreender é o aumento da demanda nas últimas décadas.

Os Jornalistas encontram-se alocados principalmente em dois setores: na Indústria Moderna (onde está classificada a Indústria Editorial Gráfica) e nos Serviços. A participação na indústria, como para os demais profissionais aqui analisados, vem caindo, como conseqüência do processo de ajustes estruturais do setor, da falta de uma clara política de crescimento econômico e de proteção da indústria nacional.

Como se mostrou, os setores que mais se abriram à participação dos Profissionais da Informação foram os Serviços e Serviços Sociais. Na realidade, isto não tem nada de específico, já que foram esses os setores que mais absorveram força de trabalho no país nas últimas décadas. A Indústria já foi um grande empregador dos Profissionais da Informação, como de outras categorias ocupacionais.

Enfim, os descaminhos da conjuntura econômica nas últimas duas décadas, as baixas taxas de crescimento econômico, a falta de uma política de investimentos e estímulos à indústria nacional levaram a esta situação de insuficiência de oferta de postos de trabalho em volume compatível às necessidades da população brasileira e a um achatamento salarial da mão de obra, mesmo daquela ocupada nos setores supostamente protegidos por suas vinculações ao paradigma da Sociedade da Informação e do Conhecimento.

Deve ficar claro para os Profissionais da Informação brasileiros que os cenários positivos de oferta de trabalho nos EUA - aumento de $94 \%$ na demanda por Analistas de Sistemas, 18\% de Analistas de Meo, $24 \%$ de redatores técnicos ${ }^{17}$ - são ainda miragens no horizonte da economia nacional.

\footnotetext{
16. Setor moderno ou mais dinâmico da indústria corresponde à agregação daqueles sub-setores industriais da Metal-mecânica, Química, Eletro-eletrônico etc. Setor tradicional, em contrapartida, reúne os sub-setores industriais de Alimentação, Têxtil etc.

17. Estimativas do Occupational Projections and Training Data do Bureau of Labor Statistics dos EUA. No caso dos bibliotecários os cenários são menos otimistas (aumento de $5 \%$ até 2008, abaixo da taxa de $14 \%$, valor médio de expansão do total de ocupações naquele país).
} 
Tabela 9. : Distribuição por grandes setores de atividade econômica do pessoal ocupado com 15 a 64 anos e jornada de 40 ou mais horas em ocupações selecionadas.

\begin{tabular}{|c|c|c|c|c|c|}
\hline \multicolumn{6}{|c|}{ Brasil 1980 - 1996} \\
\hline Ocupação de nível superior & Setor de atividade & 1980 & 1991 & 1996 & Variação 1996-80 \\
\hline \multirow{7}{*}{ Bibliotecários, arquivistas, museólogos } & Ind. Tradicional & 0,5 & 0,5 & 0,0 & $-0,5$ \\
\hline & Ind. Moderna & 2,9 & 4,0 & 1,2 & $-1,7$ \\
\hline & Serviços & 5,2 & 3,1 & 3,4 & $-1,8$ \\
\hline & Educação/Saúde & 62,2 & 64,5 & 73,1 & 10,9 \\
\hline & Adm.Pública & 23,5 & 19,0 & 17,5 & $-6,0$ \\
\hline & Demais & 5,8 & 9,0 & 4,9 & $-0,9$ \\
\hline & Total & 100,0 & 100,0 & 100,0 & - \\
\hline \multirow{7}{*}{ Analistas de sistemas e estatísticos } & Ind. Tradicional & 5,2 & 5,5 & 5,2 & 0,0 \\
\hline & Ind. Moderna & 20,6 & 18,4 & 12,4 & $-8,2$ \\
\hline & Serviços & 25,9 & 30,6 & 38,6 & 12,7 \\
\hline & Educação/Saúde & 5,2 & 5,6 & 7,0 & 1,8 \\
\hline & Adm.Pública & 12,0 & 6,4 & 6,4 & $-5,6$ \\
\hline & Demais & 31,2 & 33,5 & 30,3 & $-0,9$ \\
\hline & Total & 100,0 & 100,0 & 100,0 & - \\
\hline \multirow{7}{*}{ Analistas socioecon e prof. universitários } & Ind. Tradicional & 2,7 & 1,2 & 2,2 & $-0,5$ \\
\hline & Ind. Moderna & 10,1 & 4,1 & 6,5 & $-3,6$ \\
\hline & Serviços & 6,9 & 4,4 & 4,6 & $-2,3$ \\
\hline & Educação/Saúde & 54,1 & 71,3 & 67,3 & 13,2 \\
\hline & Adm.Pública & 8,8 & 7,5 & 5,5 & $-3,3$ \\
\hline & Demais & 17,4 & 11,4 & 14,0 & $-3,4$ \\
\hline & Total & 100,0 & 100,0 & 100,0 & - \\
\hline \multirow{7}{*}{ Jornalistas e Escritores } & Ind. Tradicional & 0,8 & 0,9 & 0,5 & $-0,3$ \\
\hline & Ind. Moderna & 45,6 & 40,1 & 36,5 & $-9,1$ \\
\hline & Serviços & 44,4 & 44,0 & 45,8 & 1,4 \\
\hline & Educação/Saúde & 2,0 & 4,5 & 5,7 & 3,7 \\
\hline & Adm.Pública & 4,0 & 5,4 & 5,6 & 1,6 \\
\hline & Demais & 3,2 & 5,1 & 5,9 & 2,7 \\
\hline & Total & 100,0 & 100,0 & 100,0 & - \\
\hline
\end{tabular}

Fonte: Censos demográficos 1980 e 1991, PNAD 92-99.

A julgar pelo passado recente, o futuro dos Profissionais da Informação no mercado de trabalho brasileiro vai depender das possibilidades concretas de crescimento econômico e da produção industrial nacional, pelos seus efeitos multiplicadores sobre os demais setores da economia.

\section{CONSIDERAÇÕES FINAIS}

Os dados apresentados neste estudo revelam que mesmo os Profissionais da Informação, caracterizados por alguns atributos de mão-de-obra que os colocam acima da média nacional, tiveram signifi- cativas dificuldades de inserção no mercado de trabalho brasileiro nas duas últimas décadas, dadas as vicissitudes da conjuntura econômica.

Devemos destacar que a inserção desses profissionais no mercado de trabalho brasileiro não dependerá apenas de uma estratégia pessoal e de formação profissional, mas também da trajetória que a economia brasileira vier a ter nos próximos anos. Nosso argumento se baseia no fato de que é somente com desenvolvimento econômico, com fortalecimento da produção industrial e com investimentos maciços nas áreas de tecnologia de ponta da indústria 
brasileira é que será possível construir um ambiente promissor para a inserção dos Profissionais da Informação no mercado de trabalho brasileiro.

Entendemos que sem uma retomada importante do ritmo de produção industrial, a economia brasileira só poderá ostentar, na melhor das hipóteses, breves e modestos (em sua dimensão) ciclos de retomada dos níveis de atividades. Apesar do processo de desestruturação de que foi vítima o setor industrial nos anos 90, pelas razões já comentadas ao longo deste texto, é preciso sublinhar que ainda possuímos um parque industrial diversificado e de dimensão suficiente para que possa liderar um processo de expansão da economia brasileira, com efeitos positivos sobre os demais setores.

Para que todos esses desafios sejam alcançados, é urgente que sejam alterados substancialmente os parâmetros pelos quais têm se guiado os formuladores da política econômica brasileira desde o início da década de 1990.

\section{REFERÊNCIAS BIBLIOGRÁFICAS}

ABREU, M.P. (Org.). A Ordem do Progresso: cem anos de política econômica republicana-1889-1989. Rio de Janeiro: Ed. Campus, 1990.

BATISTA Jr., P. N. "O Plano Real à luz da experiência mexicana e argentina". Estudos Avançados (USP). Vol. 10 n. 28 , p. 10-30, 1996.

BAUMANN, R.et al. "As tarifas de importação do Plano Real". Texto para Discussão 14. Rio de Janeiro: Fund. Getúlio Vargas, Centro de Estudos de Reforma do Estado. 1998.

BRASIL. MINISTÉRIO DA CIÊNCIA E TECNOLOGIA. Sociedade da Informação no Brasil. Brasília, 2000.

ESTADOS UNIDOS. BUREAU OF LABOR STATISTICS. Occupational projections and training data. Washington, 2000.
FILGUEIRAS, L. História do Plano Real. São Paulo: Boitempo Editorial, 2000.

GERMAN, C. O caminho do Brasil rumo à era da informação. São Paulo: Adenauer, 2000.

IANNI, O . Estado e Planejamento Econômico no Brasil. Rio de Janeiro: Civilização Brasileira, 1986. (edição revista e atualizada) n. 2, fev. 2001, Ano 2

IPEA. Políticas Sociais: acompanhamento e análise. N. 2. Fev. de 2001. Ano 2.

JANNUZZI,P.M. Status socioeconômico das ocupações brasileiras: medidas aproximativas para 1980, $1991 \mathrm{e}$ anos 90. Anais do $7^{\circ}$ Encontro Nacional de Estudos do Trabalho(CD-ROM), outubro de 2001, Salvador, 2001.

JANNUZZI, P. de M. , MATTOS, F.A. M. e NAVEGANTES, L. "Dinâmica do mercado de trabalho nos anos 80: um texto sintético". Cadernos da FACECA (PUC-Campinas). Campinas, vol.4, n.2, 1995. pp.65-86.

LESBAUPIN, I. (Org.). O Desmonte da Nação: balanço do governo FHC. Petrópolis: Ed. Vozes, 1999.

MATTOS, F. A . M. "Emprego e Distribuição de renda nas regiões metropolitanas de São Paulo e do Rio de Janeiro: anos 80". Dissertação (Mestrado). Campinas, IE/UNICAMP, ago. 1994.

MATTOS, F. A . M. e CARDOSO Jr., J. C. "Novas evidências acerca da questão distributiva pós-Plano Real". Leituras de Economia Política (7). Campinas, jul./dez.1999. p.- 29-55.

MATTOSO, J. e BALTAR, P. "Transformações estruturais e emprego nos anos 90". Cadernos do CESIT (21). IE/UNICAMP. Outubro de 1996.

MERCADANTE, A. (Org.) (1997). O Brasil pós-Real: a política econômica em debate. Campinas: Ed. da UNICAMP, 1997.

PONJUÁN DANTE, G. Perfil del profesional del nuevo milenio. In: VALENTIM, M.P. (Org) Profissionais da informação: formação, perfil e atuação profissional. São Paulo: Polis, 2000, pp. 91-106.

VALENTIM, M.P. (Org) Profissionais da informação: formação, perfil e atuação profissional. São Paulo: Polis, 2000. 